\title{
La articulación de entidades hidráulicas e instituciones políticas en la Huerta de Valencia (siglos XIII-XIX). El limitado intervencionismo de la corona
}

\author{
Tomás Peris-Albentosa \\ tomasperis@gmail.com
}

\begin{abstract}
Resumen. La comunicación recalca la importancia de la amplia autonomía local de que gozaron los colectivos de propietarios de tierras regadas y las razones que explican se adoptase este tipo de gestión. Expone que dicha autonomía no fue tan absoluta en la Huerta como suele afirmarse, sino que estuvo matizada por la imbricación de la ciudad de Valencia, los concejos rurales de la zona y la corona. Insisto, sobre todo, en la limitada intervención de la monarquía sobre las comunas de regantes, que cumplió el papel de garantizar derechos de los usuarios, ejercer un papel de arbitraje para ayudar a resolver conflictos intercomunitarios enquistados y desplegar una capacidad coercitiva que facilitase cumplir acuerdos endógenos. Planteo que la corroboración de la normativa hidráulica, por los tribunales del rey y, desde mitad del siglo XVIII, por el Consejo de Castilla, muestra una incipiente pero progresiva - injerencia del poder político central sobre las organizaciones de regantes. En base a la articulación con poderes políticos constatada, cuestiono la idoneidad del modelo dual (gestión municipal frente a manejo autónomo) que viene proponiéndose para estudiar el conjunto de sistemas hidráulicos valencianos.
\end{abstract}

Palabras clave: gestión hidráulica, articulación institucional, autonomía local, anidamiento, acequias

\begin{abstract}
This paper aims to discuss the dual institutional model commonly used to explain the Valencian historical hydraulic systems, which confronts the autonomous management of the Huerta de Valencia with the autonomous management of the rest of the irrigated areas of the kingdom. According to this research, the autonomy of the Valencian channels was limited by several powers, such as the city of Valencia, the local rural councils and the crown. The article shows a historical moderated and growing pressure of the central powers on the institutional architecture of the Huerta de Valencia.
\end{abstract}

Keywords: water management, institutions, local autonomy, nesting, irrigation channels

\section{Introducción: el contexto general valenciano}

T. F. Glick formuló, hace ya más de cuatro décadas, un modelo dual acerca del gobierno y gestión de las acequias valencianas. En él discernía entre sistemas hidráulicos en los que el manejo del agua era realizado por el municipio correspondiente -como Castellón de la Plana- y una minoría de casos en los que la gestión hidráulica era efectuada por agrupaciones de usuarios, reducido grupo de canales en el que destacan las acequias de la Vega de Valencia (Glick, 1988: XII). Desde entonces, dicho marco teórico ha resultado funcional y ha cumplido un destacado papel para guiar a las sucesivas investigaciones realizadas. Sin embargo, la madurez relativa alcanzada por la historiografía permite ya abordar la tarea de intentar trascender esta dualidad. Primero, estableciendo esclarecedores matices intermedios entre ambos extremos. Y, en segundo lugar, teniendo presente que no se trató de fórmulas organizativas inmutables, sino que fueron marcos institucionales sujetos a procesos evolutivos de diverso alcance.

Afinar en el estudio de estos aspectos es un asunto relevante ya que enlaza con el debate acerca de dos cuestiones importantes. De una parte, considerar los posibles beneficios e inconvenientes derivados de la articulación de unos colectivos de usuarios que gozaron de amplia autonomía con 
los poderes políticos, municipios y monarquía. Por otro lado, tener presente que no sólo actúan en el manejo del agua aquellas instituciones contempladas formalmente en las ordenanzas de riego y otra normativa, sino que diversos elementos también ejercieron un papel considerable a través de mecanismos informales, habitualmente opacos a la mirada del historiador ${ }^{1}$.

Mi planteamiento responde a un marco cronológico de muy larga duración y trata de combinar datos empíricos con la bibliografía disponible acerca de cuestiones teóricas. Por lo que al segundo aspecto se refiere, algunos hidraulistas decimonónicos, como Jaubert de Passá y Nadault de Buffon, ya constataron la articulación existente entre los usuarios de las aguas y los poderes políticos, defendiendo la conveniencia de un elevado grado de autonomía local (Jaubert, 1844; Nadault, 1843). Arthur Maass, por su parte, recalcó que mantener el control local ha sido uno de los principales objetivos comunitarios perseguidos por los usufructuarios de las aguas, ya que, para reducir la incertidumbre generadora de conflictos, resultaba imprescindible tanto aplicar una disciplina participativa como la existencia de vínculos adecuados con los poderes políticos (Maas\&Anderson, 2010). Elinor Ostrom, al abordar la cuestión del diseño de las instituciones que gestionan recursos de uso comunitario, también destacó los diversos nexos que vinculan a los regantes con organizaciones políticas de mayor alcance, destacando al respecto: a) la eficiencia alcanzada mediante la descentralización conseguida gracias a la autonomía local y la gestión por los implicados; b) la trascendencia del reconocimiento legal de las entidades que agrupan a los usuarios por parte del poder político para que éstas puedan llegar a ser entidades exitosas (Ostrom, 2011). Por último, Salvador Calatayud y Samuel Garrido destacan el rol positivo que el Estado ejerció en los regadíos valencianos contemporáneos (Calatayud y Garrido, 2012).

De todo ello deriva la idea que la participación de los poderes políticos (la corona y los municipios en la etapa feudal o fundamentalmente el Estado durante la época contemporánea) en el manejo de los recursos hídricos no siempre fue negativa, a condición de cumplir determinados requisitos. Dicha interacción podría haber actuado como impedimento bloqueante de la autogestión, pero habitualmente no fue así, sino que todo parece indicar que funcionó reforzando la autonomía local y dotándola de mayor efectividad.

Resulta pertinente, por tanto, replantearnos el modelo dicotómico inmutable municipal/autónomo y elaborar otro marco teórico más adecuado. Es cierto que en la mayoría de acequias fluviales valencianas la participación de las instituciones municipales en el control del agua fue muy estrecha y directa hasta mediados del siglo XIX. También lo es que en las acequias de la Vega de Valencia (excepto Rovella) ${ }^{2}$ el manejo del agua fue delegado por el municipio capitalino en la respectiva comuna d'hereters (colectivo de propietarios de tierras regadas). Pero no en menos cierto que hubo diversas acequias reales, tales como Montcada, Alzira, Villareal o Escalona, donde la participación de oficiales de la corona (baile foral o intendente borbónico) fue más vigorosa. Además, en cada uno de estos bloques cabe distinguir diversas submodalidades, según si la omnipresente autonomía local se limitara al interior de un término municipal, estuviera compartida entre diversos municipios en igualdad de condiciones o bien implicara a varios términos municipales pero se concretase mediante la hegemonía de la villa realenga de la zona y la subordinación del resto de núcleos de población beneficiarios de las aguas. En todos los casos -y esto es lo más importante-, existieron amplios niveles de autonomía que permitieron

\footnotetext{
${ }^{1}$ En el fondo de este debate, parece subyacer la consideración que la gestión óptima del agua seria aquella realizada por los propios usuarios con una autonomía absoluta, de ahí los encendidos elogios dedicados al funcionamiento de las siete acequias de la Vega de Valencia desde Borrull y Jaubert de Passá.

${ }^{2}$ Donde el manejo del agua era compartido entre el colectivo de propietarios de tierras regadas, por una parte, y una destacada institución del municipio capitalino: la Junta de Murs i Valls.
} 
desarrollar el necesario control local, evitando intromisiones inconvenientes de autoridades distantes. El actual desarrollo historiográfico permite distinguir tanto una gradación de la participación de los poderes políticos en el manejo del agua, de una parte, como la evolución de las fórmulas aplicadas, todas ellas sujetas a una fuerte dinámica histórica.

Las modalidades de monarquía que se sucedieron durante la etapa feudal tuvieron una creciente capacidad coercitiva, lo que les permitía haber ejercido una considerable injerencia sobre la gestión llevada a cabo en las acequias valencianas. Sin embargo, históricamente, ello no fue así: la corona cedió rápidamente competencias y se limitó a corroborar decisiones de los usuarios y arbitrar en los conflictos más enquistados (Peris, 2008a: 136; Maass\&Anderson, 2010: 390-391).

Las aguas superficiales no canalizadas fueron consideradas de dominio público y como tales sometidas al control real. Jaubert de Passá comentó, a mediados del siglo XIX, que la capacidad de intervención los protoestados en el aprovechamiento hídrico no fue un poder arrebatado a las comunidades campesinas, sino que respondía a la necesidad de conciliar intereses, ayudando a prevenir conflictos y propiciando fórmulas para resolverlos (Jaubert, 1847, IV: 269-273, 280-282, 302-319, 335-339, 363).

Samuel Garrido recalca que las instituciones políticas valencianas tuvieron poder para modificar el conjunto de normas que incumbían a colectivos usufructuarios de una corriente fluvial, pero casi siempre adoptaron la cautela de tratar que fueran elaboradas por los usuarios o, al menos, fuesen asumidas por ellos (2011: 35-36). En efecto, tras la conquista feudal del siglo XIII, la monarquía fue cediendo el uso de aguas a ciudades y villas (Ferri, 2002: 24). Acto seguido, diversos privilegios otorgados por la corona frenaron las potenciales injerencias de oficiales de la monarquía, incluso en aquellos canales tipificados de «acequia real», como Montcada, donde el gobierno de las aguas se dejó en manos de representantes de los usufructuarios -acequiero y doce síndicos-, mientras el Baile General quedó como simple garante de los intereses del Real Patrimonio (Jaubert, 1844, I: 317). Cuando diversos grupos de regantes eran incapaces de consensuar el reparto de aguas o existía un realengo capaz de imponerse a los señoríos vecinos, sucesivos privilegios reales sentaron jurisprudencia, como ocurrió en 1321 con el tandeo del Turia entre los pueblos-castillo y la Vega (Branchat, 1784, I: 298-300). La autogestión local llegó a estar tan arraigada que cuando, a mitad del XIX, el Ministerio de Fomento trató de dictar unas ordenanzas para Montcada, elaboradas desde Madrid, la burguesía agraria capitalina se resistió enérgicamente a ceder la autonomía de que había gozado durante más de seis siglos, arguyendo que dicha novedad «perjudicaría los intereses de los propietarios regantes, si por personas extrañas [...] se procediese a la formación de constituciones», puesto que los usuarios eran «los mejores conocedores de su justa y equitativa distribución, evitando los daños que de su poco conocimiento pudieren ocasionarse» (Archivo R.S.E.A.P.V., C-116, 1848).

Los grados de imbricación del poder político central en la gestión hidráulica, así como las modalidades mediante las cuales se materializó, fueron diversos: control algo más directo en las acequias reales, delegado en instituciones municipales en la mayoría de casos y a favor de comunas de usuarios en muy pocas acequias. Pero en todos los casos compartían el rasgo común de no pretender centralizar dicha gestión, puesto que los oficiales de la corona se limitaron a actuar «como adjuntos a la tradicional autoridad celular de los regadíos, y no en sustitución de ésta» (Glick, 1988: 134-135). La monarquía siempre prefirió dejar una amplia autonomía local. Así, Jaime I no dudó en ceder la gestión de los canales andalusíes en los territorios recién conquistados a comunidades campesinas (Branchat, III, 1786: 276-277, 300-301). Y los sucesivos 
monarcas apenas se plantearon obtener ingresos inmediatos en las nuevas acequias creadas ${ }^{3}$ : se limitaron a cobrar por autorizar a extraer caudal de los ríos y esperar que los tributos se multiplicasen gracias al sistema agrario tan productivo a que la disponibilidad de agua daba lugar.

La excepcionalidad de inspecciones realizadas por comisarios regios demuestra que no hubo una política hidráulica digna de tal nombre, desarrollada de manera sostenida por la monarquía entre los siglos XIII y XVIII. La gestión se ejerció en base a la autonomía local, de manera que la jerarquía de objetivos que guiaron el gobierno y administración de las aguas siempre se concretó en el ámbito local. Las pocas visuras realizadas por oficiales reales afectaron al reparto de caudales fluviales, incumbieron a espacios periurbanos y se produjeron, a instancia de colectivos perjudicados, en momentos en que el consenso consuetudinario se había roto. Este tipo de intervención únicamente se efectuó en coyunturas de gran inestabilidad, cuando los usufructuarios eran incapaces de reparar infraestructuras (Ferri, 2002: 154), acordar la manera de distribuir caudal o afrontar mutaciones institucionales. Así, por ejemplo, la visura a la Acequia de Alzira (1618), que precedió a la promulgación de las Ordenanzas de 1620, trató de dar respuesta a los desajustes producidos por diversas segregaciones municipales, la sucesión de una serie de años secos y las perturbaciones ocasionadas por la expulsión de la población morisca (Peris, 1992: 171-175). La comisión encargada a Gerónimo Mingot para resolver antagonismos hidráulicos en Orihuela culminó con las Ordenanzas de 1625, pero, como su aplicación resultó problemática, el intervencionismo regio fue intenso y se prolongó más de lo habitual, propiciando un «control directo por parte de la Corona [...] de una jurisdicción de aguas centralizada» (Bernabé, 2012: 7881). Aunque esta injerencia fue particularmente enérgica durante la primera mitad del XVII, no resulta peculiar de esta etapa. Son conocidas las inspecciones efectuadas en el Turia en 1318 y 1413, las de Sisternes (1584) y otros comisionados por la Audiencia (1632) en La Safor ${ }^{4}$, la visura al Serpis de 1689 (Jaubert, 1844, I: 163-167), la supervisión del Mijares de 1797 (García Edo, 1994: 248-252) o los reconocimientos de ríos valencianos realizados en el siglo XIX 5 .

Los niveles de intervención política sobre sistemas hidráulicos aumentaron notablemente entre 1608 y 1845. Ello se debió tanto a transformaciones en la estructura de la monarquía como a cambios socio-económicos o de política municipal que alteraron el consenso que vinculaba a los diversos colectivos de regantes implicados en cada sistema hidráulico (Romero-Peris-Pellicer, 1994: 185-186). Las instituciones regnícolas dosificaron su injerencia, ya que una coerción externa percibida por los usuarios como injusta y desproporcionada provocaba aumentos de solidaridades locales capaces de hacer que la violencia llegase al paroxismo. Ejemplo esclarecedor es el desacertado Auto de Buen Gobierno dictado para la acequia Mayor de Sagunto (1798), ya que la oposición comunitaria desplegada durante décadas impidió aplicar las disposiciones impuestas por la monarquía, generando un contexto de gran agresividad (Ferri, 2002: 83-86).

El peligro de intromisión política resultó particularmente potente en la Huerta de Valencia, dada la condición de la ciudad como corte del reino, así como el precoz e intenso intervencionismo a que se vieron sometidas sus instituciones municipales. También porque allí estaban los tribunales, lo que facilitaba el acceso de usuarios descontentos a la justicia real, haciendo menos necesario el papel mediador del municipio. Quizá estos rasgos expliquen la opción por una fórmula más desmunicipalizada de gestión hidráulica, poco usual en el resto del territorio valenciano, mediante la cual se preservó un altísimo grado de autonomía en manos de las comunas de usuarios.

\footnotetext{
3 Peris, 1992: 171-175; Román, 2000. La excepcionalidad de la Acequia Imperial (Aragón) demuestra lo difícil que resultaba para la monarquía obtener beneficios mediante la gestión directa del recurso agua (Pérez, 1990: 240).

${ }^{4}$ Memorial Ajustado... 1754: 28-42, 79.

${ }^{5}$ Calatayud, 1993: 72; Hermosilla (dir.), 2009: 202.
} 
Como primera manifestación de poder, la corona otorgó preeminencia a Montcada respecto a la Vega, debido a su condición de acequia real. Llauradó apunta que, al ceder el monarca este canal a los dueños de tierras (1268), se reservó privilegios que, «cedidos más tarde a dichos propietarios, han formado la base de que arrancan las preeminencias de que aún goza [...] Moncada sobre todos los demás canales de la huerta» (1884, II, 310-311). El poder regio también se manifestó atribuyendo derechos a la Vega, como hizo el 4-VII-1321, en detrimento de los regantes de aguas arriba (pueblos-castillo), que se vieron forzados a compartir el caudal del Turia, gozando cada zona, alternativamente, de toda el agua del río durante cuatro días mientras durase la carestía (Jaubert, 1844, I: 170). Pero, en lugar de competir por ejercer una gestión hidráulica directa, ciudad y corona establecieron una colaboración, mutuamente provechosa, que les permitió decidir los criterios a aplicar en la cuenca baja del Turia. Así, los tandeos con los puebloscastillo y Montcada deben contemplarse como fruto del poder político de la ciudad y de su capacidad de negociar con las instituciones monárquicas hasta lograr el favor de la corona. Otra manifestación de defensa a ultranza de intereses de la ciudad por parte de instituciones reales la constituye la visura al Turia realizada por el fiscal Sisternes (1617), quien ordenó destruir acequias ilegales, estrechar tomas de agua y reducir la dotación de diversos usuarios (el tandeo general no se cumplió) $)^{6}$.

\section{La colaboración monarquía-regantes en la Huerta para limitar violencias}

El contexto habitual en que se materializó la imbricación de instituciones de la corona en la gestión hidráulica fue de colaboración con los colectivos de usuarios. Más que antagonismo por acaparar competencias, el poder político restringió su papel a corroborar aquellos consensos alcanzados por los regantes, dotándoles de mayor fuerza jurídica, así como ejercer un rol de arbitraje para resolver disputas enquistadas.

\subsection{Garantizar derechos de usuarios antiguos y corroborar consensos}

El anhelo de desarrollo agrario a partir del satisfactorio uso de las aguas (objetivo compartido por la monarquía, los estamentos privilegiados y las comunidades campesinas) requería las premisas de flexibilidad en los mecanismos empleados para distribuir caudal y una alta seguridad jurídica (Maass\&Anderson, 2010: 37, 73-75, 402, 422). La monarquía desarrolló un cometido relevante a la hora de generar un marco jurídico que garantizase derechos hidráulicos frente a las amenazas de nuevos usufructuarios que gozasen de posición física ventajosa. Las apropiaciones de caudal por parte de quienes tenían tierras potencialmente regables aguas arriba abundaron durante las fases expansivas. La fragmentación jurídica del territorio, característica del sistema feudal, complicó la resolución de pugnas hidráulicas, no siempre fáciles de dilucidar aplicando la capacidad coercitiva de ciudades y villas realengas. En ocasiones, el poder bélico hegemónico de las milicias urbanas zanjó la cuestión, como hizo Valencia en 1413 (Glick, 1988: 206-207). Pero el uso de las armas tenía demasiados inconvenientes, haciendo preferible la intervención de la monarquía. Una muestra precoz de este tipo de actuaciones en la Huerta la constituye la orden de Jaime II (1-VIII-1318) mandando demoler azudes ilegales en el Turia «para que las aguas pudiesen pasar a [...] Valencia y su huerta» (Branchat, I, 1784: 297-298).

Aunque grupos de usuarios consensuaron instituciones hidráulicas para regirse, en determinadas coyunturas no resultó fácil castigar a los infractores a partir de mecanismos internos de supervisión, sobre todo si eran grupos numerosos o poderosos oligarcas. En contextos de

${ }^{6}$ Jaubert, 1844, I: 137-138; Borrull, 1828: 54-55, 75-76. 
inestabilidad y desafíos discordantes, el potencial coercitivo de la corona fue determinante para contener los ánimos, como expresan las Ordenanzas de Quart de 1749, promulgadas con el propósito de obligar a cumplir normas (Jaubert, 1844, II: 4-5). El proyecto de código de Mislata (1743) recalca que parte de la normativa no se estaba cumpliendo por falta de corroboración jurídica de la Audiencia (Sala, 2007: 165). Estos ejemplos confirman que los acuerdos consensuados alcanzaron plena eficacia cuando obtenían la ratificación externa de los tribunales reales u órganos políticos de la corona (Maass\&Anderson, 2010: 398; Sala, 2007: 165-166).

También las juntas de gobierno de Montcada informan de la importancia que los acuerdos endógenos fuesen corroborados por autoridades políticas. Así, el capítulo 502 de las mal llamadas Ordenanzas de 1758 (compilación normativa nunca sometida a aprobación regia) recogen que la disposición adoptada el 11-XII-1643, que permitía imponer tasas proporcionales a la superficie regada, fue presentada a la Audiencia para su confirmación como «ferma de dret». El mismo procedimiento se adoptó, en 1679, para obligar a los justicias locales a prestar auxilio a los alguaciles del canal cuando trataban de ejecutar dictámenes acordados por síndicos y acequiero (Jaubert, 1844, I: 308-309, 332-334).

\subsection{Arbitrar en disputas enquistadas, reduciendo el potencial violento}

La conflictividad hidráulica tendía a crecer a medida que disminuía el consenso que vinculaba a los usuarios. Cuando esto ocurría, durante fases de penuria aguda, sucesivas resoluciones de los tribunales reales clarificaban derechos, impulsando el proceso de regulación jurídica de los sistemas hidráulicos (García Sanz, en García Edo, 1994: 17). Además, los usufructuarios, a fin de contener antagonismos, pusieron un cuidado escrupuloso en limitar la expansión de la superficie irrigada e impedir ventas de aguas. Así, las 'ordenanzas' de Montcada prohibían enajenar caudal o consentir que otros tomasen el agua «para agenas acequias y riegos» (Jaubert, 1844, I: 159). También se adoptó una precaución exquisita para que la superficie con derecho a riego no superara el área que podía beneficiarse durante las frecuentes penurias, impidiendo que campos a los que se permitía regar durante fases de abundancia hídrica adquiriesen pleno derecho al riego ${ }^{7}$.

Excepcionalmente, cooperación y consenso dejaban paso a breves fases en las que infracciones, violencias y coerciones cobraban protagonismo. En ocasiones se llegó a incumplir masivamente acuerdos. Es lo que ocurrió en Montcada en julio de 1739, cuando las aguas debían distribuirse por oficiales delegados - «reg arreu per diputats»-; y, sin embargo, debido a considerar esta orden inapropiada, «ningun regant ni ninguna poblasió se avien volgut [atener] als preseptes [...], pues tots avien romput la orde, regant rastolls, buarets y olivars, estant ynebits $\rangle^{8}$. Incluso en esta acequia bien dotada de caudal resulta fácil aducir casos de violentos conflictos encabezados por autoridades locales?.

Las instituciones de la monarquía desarrollaron una importante función de arbitraje entre grupos de regantes enfrentados, cuyos elementos más visibles fueron las visuras efectuadas por jueces comisionados y la promulgación de ordenanzas. Con frecuencia, los tribunales de la corona ayudaron a proseguir negociaciones, cuando la capacidad de alcanzar acuerdos intercomunitarios fallaba, atendiendo instancias elevadas por parte de quienes se sentían perjudicados (Ferri, 1997: 78). Mientras que el consenso fue habitual para resolver conflictos internos, el arbitraje real lo fue para zanjar disputas que enfrentaban a canales que aprovechaban el agua de un mismo río o bien

\footnotetext{
7 Archivo Acequia Montcada [A.A.M.], Libro de difiniciones... Segundo (8-X-1695, 22-VIII-1704) y Libro Cuarto (9-V1731, 10-VIII-1734, 17-XII-1737).

8 A.A.M., Libro [Cuarto] de Difiniciones... 1730-1739, ff. 169-170.

9 A.A.M., Tercer Libre Difinicions..., acta de mediados de abril y 18-VIII-1725.
} 
graves antagonismos que amenazaban con provocar el colapso de un macrosistema (así, la Audiencia asumió la habitual función municipal de juzgar disputas de aguas en Orihuela). Elinor Ostrom insiste en la importancia de la negociación llevada a cabo «a la sombra de los tribunales», aludiendo a la capacidad de los poderes políticos externos para propiciar acuerdos difíciles de alcanzar mediante la acción endógena de los implicados, y subraya la reducción de costes que esta acción arbitral suponía (2011: 58, 200).

Jaubert recalcó la intervención que los poderes políticos habían ejercido para salvaguardar el status quo alcanzado en el aprovechamiento de aguas fluviales, previendo conflictos y conciliando intereses antagónicos (1848, IV: 302, 335). Nadault, por su parte, destacó, a partir del ejemplo del norte de Italia, que los usuarios aceptaron de buen grado la imbricación de un poder político externo dotado de capacidad arbitral (1843, III: 53-56).

La administración de justicia hidráulica se desarrolló, en primera y segunda instancia, en el ámbito local, quedando a los descontentos el derecho a apelar a los tribunales de la corona o buscar la gracia política del rey ${ }^{10}$. Resulta significativo que las oligarquías que detentaban el poder trataran de limitar esta facultad (la Junta General de Montcada del 25-VII-1663 prohibió elevar fermes de dret a la Audiencia) $)^{11}$, y la monarquía pusiese énfasis en defender este rol mediador ${ }^{12}$. El Consejo de Castilla modificó el proyecto de ordenanzas de Bennàger-Faitanar, imponiendo el derecho a apelar en los tribunales del rey: «que a ninguno se le prohíba la libertad de litigar» (Jaubert, 1844, II: 463). La mayoría de pleitos instados ante la Audiencia no se cerraron mediante sentencia porque la estrategia de los magistrados consistía en forzar acuerdos pactados entre litigantes (concordias), como se hizo en 1739 con el pleito que enfrentaba a Tormos y Montcada ${ }^{13}$.

\section{Las ordenanzas de riego: punto de encuentro entre la autonomía local y la imbricación de la corona}

\subsection{Características generales}

Las ordenanzas eran normas para guiar la actividad cotidiana en cada sistema hidráulico. Pero cualquier tipo de normativa no era, en sentido estricto, ordenanzas. Existieron preceptos estatuts, capitols - que también cumplían esta función, pero no pueden ser considerados ordenanzas. La mayoría de ítems de las mal llamadas ordenanzas medievales eran disposiciones parciales que regulaban aspectos puntuales del organigrama de gobierno o estipulaban condiciones a quien obtuviese en subasta el cargo de acequiero. No deben ser consideradas ordenanzas puesto que ni tenían un carácter global ni gozaron de corroboración regia. Las auténticas ordenanzas cabe definirlas como una normativa bastante detallada, consensuada por los regantes y reconocida por el poder político externo. Contemplaban el organigrama institucional (competencias de cada oficial y acceso al cargo), derechos y obligaciones de los usuarios, distribución de aguas, tareas de mantenimiento, infracciones y sanciones, etc. En su sentido más restrictivo, eran ordenanzas cuando recibían la corroboración de la corona, que corregía aspectos concretos y se atribuía la facultad de autorizar futuras modificaciones (Peris: 1992: 164-165). Con este significado, las ordenanzas propiamente dichas comenzaron a existir desde comienzos del siglo XVII: Se confeccionaron tras coyunturas conflictivas a fin de atajar y prever antagonismos de gran complejidad; también para conseguir fuerza legal en los pleitos

\footnotetext{
${ }^{10}$ Romero-Peris-Pellicer, 1994: 188-189; Jaubert, 1844, I: 311-313.

${ }^{11}$ Jaubert, 1844, I: 315-319; II, 341-345. El 9-IX-1678 se perdonó a Paterna la multa impuesta por apelar ante los tribunales reales una decisión del acequiero (A.A.M., Primer Libre Difinicions..., 88v-90).

12 En Castilla, De la Fuente, 2009: 120.

13 A.A.M., Libro [Cuarto] de Difiniciones... 1730-1739, 164v.
} 
sustanciados en la Audiencia (solían ser la culminación de una visura, realizada por un comisario regio, que recogía quejas de cada colectivo implicado) ${ }^{14}$.

Las ordenanzas trataron de regular todos los aspectos concernientes al funcionamiento de las acequias, pero no reflejan con exactitud como se realizó el uso de las aguas. Con esto quiero decir que el funcionamiento del sistema hidráulico debía ajustarse a sus ordenanzas; pero la lectura de estos textos normativos no permite considerarnos informados de lo que sucedió en el canal día tras día. Primero, porque las oligarquías locales utilizaban estratagemas para desvirtuar en su favor lo preceptuado (Peris, 1992). También porque, conforme la insuficiencia de caudal se agudizaba, muchas disposiciones dejaban de aplicarse y los oficiales del canal arbitraban medidas coyunturales para limitar conflictos. Así, por ejemplo, los regantes de Montcada argumentaban, en 1416, que las ordenanzas «eran para tiempos de abundancia de aguas, pero no para tiempos de escasez» (Glick, 1988: 97, 122-123).

Los procedimientos seguidos para elaborar ordenanzas justifican la denominación de punto de encuentro entre autonomía local y poder político, puesto que al fundamental consenso de usuarios se yuxtaponía la ratificación del poder político externo, así como algunas modificaciones impuestas por éste. La premisa que servía de base a cualquier ordenanza era la aquiescencia de los colectivos implicados, pero este requisito resultaba matizado por la participación de los poderes monárquico y municipal. La intervención de autoridades externas sólo llegaba a ser efectiva en la medida que fuese aceptada por los regantes, ya que en caso contrario, cuando se imponían prácticas consideradas inadecuadas por los usuarios, la injerencia política era ineficaz e incluso contraproducente (Garrido, 2011: 36; Ostrom, 1992: 52). El Auto de Buen Gobierno de la acequia Mayor de Sagunto (1798) resulta paradigmático de la relevancia del requisito consensual, puesto que su imposición por la corona -hecho poco usual en tierras valencianas- sumió a este espacio irrigado en una conflictividad extrema, que no se calmó hasta promulgar otra normativa más consensuada, las Ordenanzas de 1850 (Ferri, 2002: 70-104, 113-122). Una vez garantizada la conformidad de los usufructuarios, la corroboración de la monarquía fue cada vez más importante, puesto que dotaba a los códigos hidráulicos de mayor eficacia coercitiva. Una última característica remarcable de las ordenanzas es su perdurabilidad, rasgo que forma parte de una considerable estabilidad institucional (Romero-Peris-Pellicer, 1994: 190-191).

Gran parte de las acequias valencianas fueron acumulando normas internas en las que se agregaban decisiones adoptadas en asambleas de regantes, privilegios reales y sentencias favorables. Únicamente en Alzira, Orihuela y Escalona se pusieron en vigor, entre 1620 y 1631, ordenanzas que adquirieron fuerza jurídica después de ser aprobadas por el monarca. Desde final del XVII hasta mediados del Setecientos, las acequias de la Huerta desarrollaron una labor de clarificación normativa, aprobando capitols y estatuts corroborados por la Audiencia. Entre $1740 \mathrm{y}$ 1799, los canales de riego de la Vega elaboraron ordenanzas revisadas por el Consejo de Castilla. Y durante las décadas centrales del XIX, infinidad de acequias valencianas (que seguían rigiéndose por normas consuetudinarias o disposiciones regias puntuales) promulgaron códigos normativizados, bien sea por iniciativa propia o forzadas por el Estado liberal.

Las ordenanzas decretadas durante la revolución liberal se caracterizaron por tres rasgos. El primero es la pretensión de homogeneización institucional, tratando que todos los canales se ajustasen a un mismo patrón organizativo. Otro atributo es el respaldo legal al protagonismo del Estado, de manera que la capacidad intervencionista del gobierno reemplazó en buena parte a la anterior articulación con los poderes municipales. Finalmente, la concurrencia de los usuarios

${ }^{14}$ En la Huerta se promulgó normativa hidráulica entre 1610 y 1630, pero todavía no se ha localizado ningún texto. 
pasó a realizarse mediante comunidades de regantes, entes jurídicos teóricamente autónomos pero sujetos de hecho al control estatal y dirigidos por una elite de hacendados urbanos, ya que la participación de modestos campesinos locales se redujo considerablemente respecto los niveles que habían sido habituales durante el Antiguo Régimen (Romero\&Peris, 1992: 272). Marc Ferri califica a la gestión derivada de las ordenanzas liberales como de «participación vigilada» debido al poder atribuido al Jefe Político para presidir juntas y resolver disensiones internas. Puntualiza que las ordenanzas decimonónicas impusieron un trato más igualitario a los colectivos de usuarios, eliminando antiguos privilegios. También destaca la injerencia del Ministerio de Fomento ${ }^{15}$. En cuanto a la participación de los regantes, comparte que el componente oligárquico aumentó, puesto que medianos y grandes hacendados controlaron las juntas, restringiendo el acceso a pequeños propietarios, aunque —en sentido contrario - la existencia de normas minuciosas limitó el potencial arbitrario de los gestores burgueses (Ferri, 1997: 81-82, 158).

\subsection{E1 proceso de elaboración de ordenanzas en la Huerta}

Coyunturas especialmente problemáticas dieron lugar en la Huerta a avalanchas de nueva normativa. Ejemplos paradigmáticos son las protoordenanzas de 1415-1435 y las oleadas de códigos hidráulicos de 1610-1630 y 1699-1792.

Las ordenanzas medievales son compilaciones de sentencias favorables y la transcripción de privilegios reales, aunque también incluyen acuerdos consensuados en asambleas de regantes y cláusulas para conferir la administración del canal a acequieros que accedían al cargo mediante subasta. Borrull alude a las ordenanzas de Bennàger-Faitanar, ampliadas en 1488 y 1506, parte de las cuales pasaron a integrarse en el texto de 1732 (1828: 80). Glick cita otras ordenanzas de 1435, que en realidad son condiciones contractuales que regularon los derechos y obligaciones que correspondían, respectivamente, a acequiero y regantes (1988: 64, 26). También Mislata promulgó normativa, en 1415, para reglamentar la relación contractual de la comuna con el acequiero que adquiría en subasta anual el derecho a administrar el canal, ocupándose de mantener infraestructuras y distribuir caudal a cambio de percibir el cequiaje y parte de las multas ${ }^{16}$. En Quart también se elaboró normativa en 1350 (Jaubert, 1844, I: 392).

Entre 1610 y 1630, tras la expulsión de los moriscos, debió producirse un notable reajuste institucional en la Huerta, coincidiendo con lo constatado en otras acequias (Alzira, Orihuela o Escalona), lo que autoriza a pensar en un esbozo rudimentario de política hidráulica llevada a cabo por la monarquía durante estos lustros de gran inestabilidad. Un elemento relevante del esfuerzo adaptativo realizado para atenuar conflictos es la reforma impulsada por el fiscal de la Audiencia, Melchor Sisternes, a raíz de la visura efectuada al Turia en 1617. Otro componente fue la actualización de normativa interna en cada canal, proceso del que tenemos constancia pero que todavía no ha sido estudiado (por ejemplo, una Junta de Electos de Tormos, del año 1839, alude a que el código entonces vigente había sido elaborado en 1630; Guinot, 2005: 120-125).

El principal ajuste institucional se produjo en la Huerta durante el siglo XVIII, cuando la mayoría de acequias elaboraron ordenanzas validadas por la corona, que afianzaron el protagonismo de la oligarquía urbana. Su promulgación atajó las amenazas que para poder que detentaba la elite capitalina significó el desarrollo agrario iniciado al final del Seiscientos, así como los cambios políticos derivados de la implantación de la monarquía borbónica (Romero\&Peris, 1992: 266-267; Peris, 2003c: 134).

\footnotetext{
15 Órgano estatal que «dejó en ocasiones los capítulos penales de las ordenanzas en suspensión» (Ferri, 1997: 88).

${ }^{16}$ Sala, 2007: 49 y siguientes. Una parte se recoge literalmente en las Ordenanzas de 1751.
} 
Favara elaboró unos Capitols e Ordinacions en respuesta a la intensa conflictividad padecida. El proceso de confección se inició en 1690, protagonizado por un grupo de comisionados, en el cual los representantes campesinos eran clara minoría, que expusieron sus resultados ante la Junta General. Y culminó en 1701, con su aprobación por parte del Portantveus de General Gobernador, autoridad política que se limitó a verificar que ningún artículo entraba en contradicción con los Fueros todavía vigentes (Jaubert, 1844, I: 413-414).

Rovella inició su actualización normativa en 1699, poco antes de la guerra de Sucesión. Es importante retener la fecha a fin de evitar el error de atribuir el proceso ordenancístico exclusivamente a los cambios políticos introducidos por la monarquía borbónica. Debe concederse importancia al proceso de intensificación agrícola, perceptible desde final del Seiscientos, y a las tensiones sociales que lo acompañaron. El núcleo fundamental de este código, validado por la Audiencia, debe interpretarse como confirmación jurídica del creciente dominio detentado por electos (con neto predominio de la oligarquía urbana) en detrimento del tradicional poder ejercido por la Junta General. Estos Capitols y Ordinacions informan del status quo vigente a final del Seiscientos: gestión oligárquica por juntas de gobierno, sin que existiese una normativa detallada y clara, lo que beneficiaba a la élite de propietarios con poder e influencia suficiente como para imponer sus intereses. Los problemas arrastrados (resistencias campesinas, conflictos para nombrar síndico, déficit hídrico, etc.) impulsaron a la minoría dominante a reforzar su hegemonía, dotarla de un carácter institucional y certificarla mediante la corroboración real a fin de hacerla perdurable. Un aspecto relevante es el interés de la oligarquía capitalina en controlar la Junta de Electos, tanto mediante la clara mayoría numérica alcanzada en esta institución como debido al carácter vitalicio de sus miembros, que contrasta con el ejercicio bianual del cargo por los representantes de zonas rurales. Otro elemento esencial es la importancia que se atribuye a la corroboración de la normativa por parte de la monarquía. En 1699 se acordó que los «capitols [...], per a la major validitaty observancia, sien decretats y autorizats per el tribunal competents. Con el paso de los años, esta medida debió parecer insuficiente y, siguiendo los pasos de otras acequias de la Huerta, elevaron su normativa al Consejo de Castilla, en la década de 1770, para que le otorgase el máximo rango: ordenanzas aprobadas por el rey. Dicho órgano político accedió en 1778, pero impuso diez artículos nuevos (Jaubert, 1844, II, 323-328).

Los códigos elaborados por Rovella y Favara influyeron en el resto de acequias de la Huerta, mimetismo que se detecta en la repetición literal de artículos. Las ordenanzas de Quart comenzaron a confeccionarse en 1698, justificándose la reforma institucional por la conflictividad que se experimentaba y las dificultades para atajarla, debido a la indefinición y otras carencias de la normativa vigente. Fueron aprobadas por el alcalde mayor de Valencia en diciembre de 1709, un par de años después de la entrada en vigor de la Nueva Planta, en un contexto de gran confusión política e incertidumbre jurídica, apenas comenzaron a percibirse las primeras manifestaciones de absolutismo exhibidas por los militares nombrados para gobernar la ciudad y el reino (Giménez, 1999). La repetición literal de artículos de Rovella denota cierto mimetismo, que se explica por el afán de la oligarquía capitalina en disponer de un respaldo jurídico que garantizase su continuidad en el ejercicio del poder hidráulico (Jaubert, 1844, II: 3-32, 299-328).

El código de Bennàger-Faitanar, elaborado en 1732, significa un cambio drástico, puesto que fue la primera normativa en ser elevada a la consideración del Consejo de Castilla, órgano político que otorgó su aprobación en 1740. Como en otros casos, recogían disposiciones que habían ido consensuándose desde los últimos siglos medievales: 1488, 1506, etc. (Borrull, 1828: 80). No se trató de una validación rutinaria de normativa remitida por usuarios, puesto que el Consejo 
únicamente accedió a aprobarlas después de un minucioso análisis y, a instancia de la Audiencia, impuso diversas modificaciones.

El proceso de elaborar ordenanzas para Mestalla fue particularmente laborioso, lo que permite distinguir varias fases. Se inició en 1734, como un desarrollo normativo endógeno. Pero el conjunto de disposiciones adoptadas por los usuarios no se sometió a aprobación real hasta 1769 y la corroboración regia se retrasó hasta 1771. El motivo explicitado para justificar la codificación es la virulenta y perturbadora conflictividad existente a comienzos del Setecientos, originada en parte por la inoperancia de una normativa desfasada, fragmentaria y opaca (Jaubert, 1844: I, 399401).

Sobre las Ordenanzas de Mislata, Canales de Riego... se limita a incluir el texto aprobado por el Consejo de Castilla en 1751. En su introducción aclara que fueron presentadas por los usuarios y el Consejo, en base al informe de la Audiencia, procedió a «reformarlas [...] y limitarlas, como nos ha parecido conveniente» (Jaubert, 1844, II: 33-70).

La confección de las Ordenanzas de Rascaña la iniciaron los regantes en 1753, pero no culminó hasta su aprobación por el Consejo de Castilla en 1761 y la confirmación regia en 1765, después de haber introducido diversas modificaciones (Jaubert, 1844, I: 417).

En Montcada, quizá por su carácter de acequia real, no se elaboró un código renovado para someterlo a la aprobación del monarca. Lo que hubo fue un proceso de recopilación de normativa tradicional no derogada explícitamente por los regantes. La compilación de Felip Mateu (1758) ha cumplido desde entonces la función de código fundamental, figurando en la obra de Jaubert (1844, I: 158-379) y siendo reimpresa en 1910 y 1972. Dicho repertorio se hizo por encargo de la junta de síndicos celebrada el 10-X-1757 para resolver la «grave necesidad que ocurría de formar un Libro [...] en el que se noten las noticias y reglas por donde se govierna». Como motivo, se alude a los desperfectos del epítome confeccionado por Valls en 1771 (Ordenanzas..., 1972: 146). Dicho compendio comienza con los privilegios reales acumulados desde tiempos medievales y -a partir del artículo 35- siguen «capítulos antiguos que no están revocados». En otros bloques figuran las disposiciones del «readreso» para distribuir aguas, recogido por Andreu Puig en 1658, un inventario de tierras regadas, así como artículos aprobados por sucesivas juntas generales de regantes (Jaubert, I: 182-185, 348-351, 379-388). El principal motivo argüido para justificar la actualización del libro confeccionado por Valls, pese al poco tiempo transcurrido, es «no estar escrito con letra legible»; pero es fácil suponer que el propósito del trabajo encomendado a Mateu era traducir al castellano la compilación de normas - escritas en latín y catalán-, a fin de facilitar su comprensión a la élite castellanizada que dirigía el canal y los oficiales de la monarquía (Ordenanzas..., 1972: 11). No existió, pues, un proceso de reajuste institucional en sentido estricto, sino que se trata de una presentación más inteligible de normas acumuladas a fin de dotarlas de mayor eficacia jurídica. Esta falta de corroboración por parte de los órganos políticos explica que el Ministerio de Fomento tratase de confeccionar, a mediados del XIX, unas ordenanzas para Montcada en las que trató de imponer una férrea supervisión estatal (Archivo R.S.E.A.P.V., sign. C-116, 1848).

El último reglamento corroborado por la monarquía, ya en contexto de crisis del Antiguo Régimen, fue el de Chirivella, que formaba parte del sistema hidráulico de Mislata. Se trata de un código escueto, que recibió la validación jurídica y política de la corte en 1792. La Junta de Electos quedó autorizada a proponer actualizaciones, pero el Consejo de Castilla se reservó la facultad de permitir cualquier modificación (Jaubert, 1844, II: 378-379). 
La avalancha de ordenanzas producida en territorio valenciano entre 1839 y 1851 apenas afectó ya a la Huerta. En parte, porque el modelo organizativo desarrollado en esta comarca durante el XVII (esporádicas juntas generales con potestad formal y poder efectivo en manos de comisiones de electos bastante desligadas del poder municipal), consagrado jurídicamente entre 1699 y 1792, fue el que se generalizó al conjunto del País Valenciano durante la revolución liberal (Ferri, 1997: 87-88). La única acequia de la Vega en redactar ordenanzas fue Tormos, que no había realizado este acomodo institucional en el siglo XVIII. El Ministerio de Gobernación obligó a modificar los artículos $2^{\circ}, 6^{\circ}$ y $27^{\circ}$, relativos a quien gozaría de voto en junta general (propietarios de más de dos hanegadas), miembros de la junta particular (cada electo sería votado en asamblea de la zona representada) y otorgaba facultades a la junta particular para repartir agua durante las carestías (Jaubert, 1844, II: 97-99).

\subsection{Características de las ordenanzas de la Huerta}

El primer rasgo relevante es su carácter consensual, atributo que deriva de la finalidad de atenuar situaciones conflictivas de gran complejidad. Las de Favara resultan elocuentes de la importancia que la normativa estuviese consensuada, ya que exigían la unanimidad de los representantes: «no es puguen derogar [...], si no és per la junta plena dels quince elets, votant dita derogació ab vots secrets y nemine discrepante» (Jaubert, 1844, II: 190).

Otra característica de estos códigos es su persistencia temporal, ya que las recopilaciones promulgadas entre 1699 y 1843 recogen una parte importante de disposiciones anteriores y su vigencia ha llegado hasta nuestros días. Jaubert ya expresó la gran estabilidad que caracteriza a las normas constitucionales de cualquier macrosistema (1847, IV: 323-324; Peris: 1992: 279). Este hidraulista recomendó la permanencia de los reglamentos reguladores del aprovechamiento de aguas, puesto que su validez venía avalada por un consenso reforzado por el capital social que significaba una experiencia satisfactoria durante generaciones (Jaubert, 1844: I, 391). Dicha avidez de estabilidad se constata, por ejemplo, en la acequia de Quart, cuyas Ordenanzas de 1749 recogían parte del articulado puesto en vigor en 1350, 1488-1506 y 1739 (Jaubert, 1844: I, 392). También en Mislata se confirma la continuidad, hasta el extremo que parte de las Ordenanzas de 1751 eran artículos literales que habían entrado en vigor en 1415 o 1629 (Sala, 2007: 49). También Montcada mantenía en 1758 numerosos «capítulos antiguos [...] que no están revocados» y normas tradicionales para distribuir caudal. Lo mismo ocurría en Bennàger-Faitanar, donde la mitad del articulado de 1732 eran acuerdos pretéritos que se mantenían en vigor. Por último, resulta significativo que quienes detentaban el poder hidráulico en Mestalla manifestasen considerable afán para que la normativa aprobada en junta general ya no sufriese «la menor alteración» (Jaubert, 1844, I: 182-202, 399-401).

Otro rasgo fundamental de las ordenanzas de la Huerta es la importancia que se atribuyó a la corroboración real a partir de 1740, cuyo significado histórico combina gran parte de validación de normativa elaborada por usuarios con cierta dosis de intervencionismo regio. La injerencia monárquica fue menor - y más discreta y opaca - durante los siglos XIV-XVI, para hacerse mayor y más explícita entre el XVII y el XIX. A partir de la revolución liberal, la capacidad de intromisión del poder político estatal llegó a ser jurídicamente muy alta, pero sólo llegó a materializarse de hecho en ocasiones excepcionales caracterizadas por una peligrosa conflictividad entre usufructuarios (la intervención directa de autoridades estatales se reservaba, como última instancia, para cuando los regantes eran incapaces de alcanzar el mínimo consenso; Ferri 2002: 158-159). 
La corroboración de la monarquía fue buscada por los hereters de las acequias debido a varias razones. Primero, porque la ratificación de la Audiencia confería a los acuerdos endógenos mayor eficacia jurídica en los conflictos intercomunitarios que pudieran enfrentarles con otros regantes. También, porque la falta de validación real restaba capacidad coercitiva a la normativa y dificultaba imponer a los infractores sanciones proporcionadas. Como se explicita en el código proyectado para Mislata (1743), las normas acordadas en 1629 no podían «ponerse en práctica por defecto de facultad Real», por lo que la junta general del 11-VI-1730 decidió se hiciesen «Ordenanzas para el buen Gobierno, y conservación de dicha Acequia», dando poder para que, «en vista de los Capítulos y Ordenanzas antiguas», obtuviesen «facultad Real para su puntual observancia» (Sala, 2007: 165). Más elocuente del papel reservado a las instituciones monárquicas es la afirmación de los regantes de Montcada, quienes, ante la voluntad intervencionista del Ministerio de Fomento en 1848, expresaron que si tradicionalmente habían «recurrido algunas veces a la autoridad» política central, «ha sido tan sólo para que apoye y sostenga sus determinaciones societarias» (Archivo R.S.E.A.P.V., C. 116, año 1848).

Las modalidades de validar normativa hidráulica por la corona evolucionaron. Primero se buscó corroborar disposiciones sueltas, por parte de la Gobernación en tiempos medievales y de la Audiencia desde comienzos del XVI. Durante el Quinientos y el Seiscientos fue habitual la ratificación jurídica de conjuntos de normas por parte la Audiencia. Desde mitad del XVIII, en cambio, se pasó a someter los proyectos de ordenanzas al Consejo de Castilla, organismo que corregía algunos ítems propuestos por la élite que dirigía las acequias e incluso llegó a introducir artículos nuevos. La corona se reservó, desde 1740, la facultad de autorizar modificaciones en las ordenanzas, de manera que los usuarios quedaban obligados a solicitar cualquier cambio: quizá ello explique - precisamente - las escasas iniciativas emprendidas por las acequias valencianas para renovar normativa, de manera que resulta elocuente que esta práctica no se haya reproducido después de la avalancha legislativa acaecida entre 1740 y 1843.

\section{Las instituciones de la corona que ejercieron competencias sobre la gestión hidráulica}

A menudo se olvida que diversos organismos de la monarquía, y los correspondientes oficiales reales, también intervinieron en el manejo del agua realizado en las acequias de la Huerta de Valencia. Destacan al respecto el papel desarrollado por la Corte del Gobernador, la Bailía General, la Audiencia valenciana, el Intendente borbónico durante el siglo XVIII y el Jefe Político en las décadas centrales del XIX ${ }^{17}$.

\subsection{La Corte del Gobernador}

Era una institución en la que se delegaron funciones gubernativas, pero que también recibía apelaciones a sentencias de jueces ordinarios, que tuvo atribuciones sobre las acequias hasta 1707. En el ámbito de la gestión hidráulica, otorgó permiso para celebrar asambleas de regantes y se informaba de su desarrollo (Guinot, 2005: 110-113), recibía apelaciones a dictámenes del acequiero y ejerció un importante papel arbitral (Jaubert, 1844, I: 311). También vigilaba que se ejecutasen las órdenes reales relativas al uso de las aguas (Glick, 1988: 178) y únicamente este organismo podía autorizar el endeudamiento censal de las comunas (Jaubert, 1844, I: 190-191). Según Glick, en los últimos siglos medievales, el gobernador «promulgaba edictos a voluntad de la ciudad, [...] incluso en contradicción con los propios privilegios reales» (1988: 209-210).

${ }^{17}$ Aunque no se debe negligir el rol político ejercido desde el Consejo de Castilla. 


\subsection{La Bailía General}

Era la institución encargada de administrar el Real Patrimonio, incluyendo las aguas públicas (Branchat, 1784, I: 512; Jaubert, 1844, I: 519-525). Su intervención fue más directa e intensa en Montcada, debido al carácter de acequia real, ya que la jurisdicción estuvo compartida entre Acequiero y Baile (Branchat, 1784, I: 324-328; Jaubert, 1844, I: 317). En virtud del privilegio de 1358, decidía criterios para distribuir agua durante las sequías y defendía las rentas que la corona obtenía de los molinos (Glick, 1988: 177-178). Tras la Nueva Planta, siguió ejerciendo atribuciones, como demuestra la junta celebrada el 27-IX-1723, en la que impuso que no se nombrase acequiero sino que se debía prorrogar a quien venía ejerciendo el cargo interinamente ${ }^{18}$. En la Vega, el Baile defendió al Patrimonio Real (rol reforzado en 1311 y 1321) y ejerció facultades de juez de ríos desde 1369 (Branchat, 1786, III: 142, 150) ${ }^{19}$. Jaubert testimonió la pretensión de este oficial de ejercer mayores competencias en la Huerta a comienzos del XIX, a lo que se opuso la burguesía urbana que detentaba el control hidráulico (define textualmente este intento como abrir una "puerta peligrosa a las reformas que continuamente tiende a introducir la autoridad hasta aquí desconocida del corregidor y baile general» (1844, I: 474).

\subsection{La Audiencia}

Surgida en 1506 y mantenida tras la Nueva Planta, cumplió tareas de asesorar a las autoridades políticas y ejercer de alto tribunal del reino. Como tal, desempeñó importantes funciones de regulación hidráulica y corroboró acuerdos de usuarios; también desarrolló un notable papel arbitral, fomentando acuerdos entre litigantes, y ejerció un considerable control sobre regulaciones de aguas intercomunitarias (incluso llegó a imponer criterios coercitivos).

En cuanto a la validación de acuerdos internos, a fin de conferirles fuerza jurídica, el procedimiento habitual seguido por las comunas de la Huerta fue acudir a la Audiencia. Así, la capacidad de síndicos y acequiero de Montcada para imponer tasas fue ratificada mediante una ferma de dret instada ante la Audiencia en 1643 (Jaubert, 1844, I: 308). También las ordenanzas de Bennàger-Faitanar (1732) prescribían que las cuentas anuales fuesen auditadas por la Audiencia, a fin de asegurar que respondían a exigencias de «equidad y justicia», evitando abusos administrativos gravosos para los regantes. Lo mismo ocurrió con el dictamen de la comisión formada para reformar tomas de agua en Montcada con el propósito de evitar iniquidades que sufrían los usuarios inferiores o jussans. Hasta tal punto fue habitual, que muchas disposiciones importantes adoptadas por Montcada (como la concordia de 1658 para distribuir caudal) culminan con la expresión «que la presente concordia se haya de decretar y autorizar por [...] la Real Audiencia $\rangle^{20}$, validación que aunaba las ventajas de mayor fuerza legal y garantía de conservación a largo plazo del documento. Cuando el alguacil de Montcada se quejó, en abril de 1734, que los justicias no le auxiliaban cuando trataba de ejecutar multas, la junta de síndicos decidió 〈posar petisió en la Audiènsia»" ${ }^{21}$. Era también el tribunal al que podían apelar los disconformes con los dictámenes del acequiero y síndicos en asuntos de considerable enjundia (Jaubert, 1844, I: 150).

La Audiencia también cumplió una inestimable función arbitral. Por una parte, la tardanza en dictar sentencia y los gastos que ello implicaba estimulaban a cerrar litigios mediante concordias aceptables para las partes enfrentadas. Por otro lado, imponía criterios para finiquitar conflictos intercomunitarios enquistados o demasiado peligrosos. Buen ejemplo es la cuestión suscitada por

\footnotetext{
18 A.A.M., Tercer Llibre Difinicions..., f. 36.

19 Branchat, 1786, III: 155-156; 1784, I: 267-269; Borrull, 1828: 11-12.

20 Jaubert, 1844, I: 203-206, 213, 464, etc.

21 A.A.M., Libro Difiniciones Cuarto, 20-IV-1734, f. $77 \mathrm{v}$.
} 
la reconstrucción del azud de Montcada en 1673-1674: los munícipes de Valencia y los síndicos de la Vega se opusieron, por lo que dicha comuna puso «suplicación en la Real Audiencia [...] pidiendo [...] facultad [...] para reedificar dicho azud y almenara»; la sentencia (1-XII-1673) autorizó las obras, tras constatar que las acequias inferiores no resultarían perjudicadas (Jaubert, 1844, I: 321-325). Las actas de las reuniones dan fe de la fuerza jurídica de la Audiencia para atajar conflictos enconados. Un ejemplo elocuente es que el síndico de la población de Montcada presentó notificación de la Audiencia ordenando «no se innovara ninguna cosa en la obra se avia delliberat fer en $[. .$.$] una de les almenares [...] del Colom», por lo que la Junta de Síndicos se vio$ obligada a desdecirse («que no es treballe en previndre cals, pertrets y altres coses [...] asta altra nova provisió de la Real Sala»), e inició trámites para argumentar en dicho tribunal ${ }^{22}$.

En ocasiones excepcionales, cuando se padecía penuria extraordinaria de aguas y la conflictividad alcanzaba niveles alarmantes, la Audiencia comisionó a un fiscal para realizar una visura e imponer soluciones drásticas, como hizo Melchor Sisternes en la cuenca del Turia en 1617 (Jaubert, 1844: 137-138).

\subsection{E1 Intendente borbónico}

Asumió las atribuciones propias del Baile foral desde 1718 y adquirió nuevas atribuciones administrativas y judiciales relativas al funcionamiento de las acequias en 1749. Su autoridad incumbió de manera especial a Montcada, ya que «a excepción de los negocios comunes [...], en todas las demás causas y pleytos relativos a la acequia y sus aguas debe conocer el Intendente» (Branchat, 1784: I: 325). Esta intromisión fue endémica e intensa, afectando tanto a asuntos internos como a conflictos con la Vega. Así, llegó a impedir que tomara posesión el acequiero elegido por los regantes en $1724^{23}$, o exigió dar paso por su azud a las maderas que bajaban por el Turia: la junta de síndicos recibió mandato del Intendente (28-VII-1739) ordenando dar «cada dia als dueños de la madera 8 hores de aigua per a poder aplegar a Valènsia»; pese a que una delegación fue a exponerle la sequía que padecían los campos, la respuesta fue que «no avia altre albitre, y que no podia deixar-se de donar», puesto que «era orden del Intendent $\rangle^{24}$.

En la Vega, el Intendente se limitó a sentenciar en primera instancia pleitos intercomunitarios o defender intereses del Patrimonio Real, lo que en la práctica solía consistir en obligar a las acequias de aguas arriba a dejar pasar agua para que los molinos periurbanos funcionasen durante las peores sequías ${ }^{25}$.

\subsection{E1 Jefe Político}

Este instrumento centralizador del Estado liberal ejerció considerables atribuciones en las acequias que limitaron la tradicional autonomía de los usuarios. Las reales órdenes de 1836 y 1839 le encargaron atajar la conflictividad que se experimentaba, instándoles a hacer cumplir a los regantes «las ordenanzas, reglamentos y disposiciones superiores» en materia de aguas. Ello le confirió un notable protagonismo en el proceso de reorganización administrativa experimentado a mitad del siglo XIX, incluyendo redactar ordenanzas, autorizar obras y vigilar el funcionamiento cotidiano de las acequias ${ }^{26}$.

\footnotetext{
22 A.A.M., Libro Difiniciones Cuarto, f. 99v.

${ }^{23}$ A.A.M., Segon Llibre Difinicions..., f. 44v.

24 A.A.M., Libro de Difiniciones Cuarto, ff. 170-174.

${ }^{25}$ Branchat, 1784, I: 267, 322-324; 1786, III: 310-311.

${ }^{26}$ Ferri, 1997: 78-79, 88 y 158; Polop, 2007: 28.
} 
Su intervencionismo fue menor en la Huerta que en otras acequias valencianas; pero, aún así, se hizo notar. Las Ordenanzas de Tormos (1843) le encargaban presidir juntas generales, así como "proponer al gobierno las reformas que la esperiencia acredite ser necesarias, [...], con tal que [...] se acuerden por mayoría de dos terceras partes de los concurrentes a la junta general» (Jaubert, 1844, II: 77, 331-333). Una de las iniciativas en que se percibe su implicación fue impulsar el fallido Sindicato General del Turia, apoyando la iniciativa de la burguesía capitalina organizada en la Real Sociedad Económica de Amigos del País de Valencia, y realizando inspecciones a la cuenca del Turia para detectar aprovechamientos ilegales (Sanchis, 2013).

\section{Conclusión}

En los epígrafes anteriores se ha constatado como también en las acequias de la Huerta existió, entre los siglos XIII y XIX, una creciente participación de las instituciones de la monarquía en el manejo del agua, aunque habitualmente tuvo una intensidad baja. Si a ello añadimos la imbricación de las instituciones municipales de la zona en el gobierno de las acequias, ${ }^{27}$ la idea de autonomía total de las acequias de la Huerta, gestionadas exclusivamente por colectivos de usuarios, absolutamente al margen del poder de las instituciones políticas, pierde contundencia y reclama ser estudiada con mayor atención.

En todas las acequias fluviales valencianas, la autonomía local fue un rasgo omnipresente, dado que la organización institucional y la administración ordinaria tuvieron un carácter descentralizado, participativo y cooperativo. En unos casos, dichas atribuciones se ejercieron -en mayor medida- a través de la respectiva corporación municipal; en otros, las competencias hidráulicas se delegaron en organizaciones específicas que agrupaban a los usuarios de las aguas; finalmente, en muchas acequias se aplicó toda una gama de fórmulas híbridas intermedias.

La siempre vigente autonomía local -con una orientación más o menos municipalista- se entiende por la concurrencia de toda una serie de causas. En primer lugar, porque facilitaba adaptarse a las condiciones locales y permitía evolucionar según lo hicieran éstas. También porque facultaba poner en marcha mecanismos operativos complejos y flexibles, mediante los cuales adaptarse a la marcada irregularidad pluviométrica y repartir un caudal muy fluctuante de forma equitativa. En tercer lugar, porque posibilitaba atender la urgencia de las actuaciones requeridas, tanto a la hora de reparar desperfectos, distribuir caudal como administrar justicia. Finalmente, debido a la necesidad de limitar el gran potencial conflictivo inherente al uso de las aguas, dada la ventaja de la autosupervisión y la precisión de alcanzar consensos efectivos.

La articulación de los poderes políticos con las organizaciones de regantes fue buscada por los usuarios, de manera que, en lugar de pretensiones intervencionistas, lo que hubo fue más bien una participación arbitral demandada por los propietarios de tierras regadas en coyunturas en las que no se alcanzaban los necesarios consensos internos. Dicho nexo resultó funcional, sobre todo, porque evitó los peligros de una homogeneización impuesta por un poder político distante, propiciando cierta solvencia descentralizadora. También porque la capacidad coercitiva de las instituciones municipales y de la monarquía facilitó que los acuerdos colectivos consensuados por los regantes se cumpliesen, incluso por aquellos sectores oligárquicos poco dispuestos a acatarlos.

\footnotetext{
${ }^{27}$ En la Huerta existió un doble nexo que relacionó a instituciones municipales con colectivos de regantes: en un nivel superior, con la ciudad; en otro inferior, con los municipios rurales. La participación de entidades municipales no se efectuó con la misma intensidad en todas las acequias; pero en todas ellas existió una imbricación intermitente (mayor durante las carestías de agua) y selectiva, que tuvo el doble carácter de injerencia y participación (véase al respecto Peris, 2014).
} 
Como muestra el esquema siguiente, la organización hidráulica en la Huerta de Valencia fue bastante más compleja —y la autonomía de los usuarios menos absoluta— de lo que ha venido admitiendo la historiografía, que enfatiza sobre todo el papel desarrollado por los campesinos regantes mediante su participación en asambleas de usuarios (Junta General). Primero, debe tenerse en cuenta que la participación en este tipo de reuniones se limitaba exclusivamente a los propietarios de tierras regadas, quienes solían arrendar sus campos a los campesinos que las cultivaban. En segundo lugar, la verdadera capacidad decisoria correspondía a un reducido grupo de grandes terratenientes, miembros de la élite urbana (influyentes instituciones religiosas, poderosos nobles, etc.), bien informalmente y a título individual o bien como miembros de la comisión reducida o junta de gobierno (denominada Junta de Electos en la mayor parte de las acequias de la Vega). La complejidad institucional también procede del hecho de tener que contemplar la articulación con los poderes políticos, lo que incluye tanto la participación del municipio de la capital y los concejos rurales de la zona irrigada como el concurso de organismos de la monarquía.

Corona
Instituciones municipales de la ciudad de Valencia
(Grandes terratenientes, miembros de la élite urbana)
Cort dels Sequiers o Tribunal de las Aguas, que agrupa a las 7 acequias de la Vega
Junta General de cada sistema hidráulico
Junta Particular o de electos de la respectiva acequia
Oficiales de riego de cada canal: síndico, etc.
Sectores de cada sistema hidráulico: zonas, brazales, etc.
Municipios rurales
Propietarios de las tierras regadas
(Campesinos cultivadores)

Fig. 1. El gobierno de las aguas y la gestión hidráulica en la Huerta de Valencia: articulación con poderes políticos y anidamientos horizontales. Entre paréntesis las modalidades informales de participación, no contempladas por la normativa pero practicadas de hecho.

De lo expuesto a lo largo de la presente comunicación debe inferirse que la articulación de la corona en las acequias de la Huerta de Valencia fue respetuosa con la amplia autonomía local de que gozaron las organizaciones de usuarios. Se trató de una participación mutuamente provechosa, tanto para los intereses de la monarquía como de los regantes, ya que la imbricación de los oficiales reales: 
a) ayudó a desarrollar un marco jurídico que contribuía a garantizar los derechos hidráulicos de cada uno de los colectivos implicados en el aprovechamiento de las aguas;

b) ejerció un importante papel de arbitraje que concurrió a apaciguar los conflictos intercomunitarios;

c) la capacidad coercitiva de la corona facilitó el cumplimiento efectivo de los acuerdos endógenos adoptados por los usuarios.

Cabe concluir, por tanto, que la serie de privilegios reales, sentencias judiciales y órdenes de los oficiales reales no solo afectaron al aprovechamiento global del agua en la cuenca baja del río Turia -como se venía admitiendo-, sino que también llegó a incumbir -aunque fuese de manera indirecta- al manejo interno del agua en cada una de las siete acequias que irrigaban la Huerta de Valencia.

\section{Referencias}

Borrull, F.X. (1828): Discurso sobre la distribución de las aguas del Turia..., Valencia, B. Monfort.

Branchat, V. (1784-1786): Tratado de los derechos y regalías que corresponden al Real Patrimonio del reyno de Valencia, 3 vols., Valencia, Imprenta Orga.

Calatayud, S. (1993): El regadío ante la expansión agraria valenciana: Cambios en el uso y control del agua, Agricultura y Sociedad, 67, 47-92.

Calatayud, S. y Garrido, S. (2012): Negociación de normas e intervención estatal en la gestión del regadío: la acequia Real del Júcar a mediados del siglo XIX, Hispania, LXXII, 240, 95-118.

De la Fuente, C. (2009): El agua y los concejos castellanos en la época Moderna, en Marcos Martín (coord.): Agua y sociedad en la época moderna. Valladolid, Universidad, pp. 87-120.

Ferri, M. (1997): Reorganización de los regadíos valencianos en el siglo XIX: las ordenanzas liberales de la provincia de Valencia (1835-1850), Áreas, 17, 78-89.

Ferri, M. (2002): Terratinents, camperols y soldats. Regadiu y conflicte social al Camp de Morvedre, Valencia, Universidad.

García Edo, V. (1994): Derechos históricos de los pueblos de la Plana a las aguas del río Mijares, Castellón, Diputación.

Garrido, S. (2011): Las instituciones de riego en la España del este. Una reflexión a la luz de la obra de Elinor Ostrom, Historia Agraria, 53, 13-42.

Giménez, E. (1999): Gobernar con una misma ley..., Alicante, Universidad.

Glick, T.F. (1988): Regadío y sociedad en la Valencia medieval, Valencia, Del Cenia al Segura (primera edición inglesa 1969).

Hermosilla, J. (dir.) (2002-2009): Regadíos Históricos Valencianos, 12 vols., Valencia, Generalitat. 
Jaubert de Passà, F.J. (1844): Canales de riego de Cataluña y Reino de Valencia..., 2 vols, Valencia, B. Monfort.

Jaubert de Passá, F.J. (1846-1847): Recherches sour les arrosages chez. les peuples anciennes..., 4 vols., Paris, Bouchar\&Huzard.

Llauradó, A. (1884): Tratado de aguas y riegos, 2 vols., Madrid, Moreno\&Rojas.

Maass, A. y R.L. Anderson (2010): Los desiertos reverdecerán. Estudio comparativo de la gestión del riego en el Mediterráneo españoly el Oeste norteamericano, Valencia, Conselleria de Cultura.

Memorial ajustado del pleyto que sigue [...] la villa de Oliva..., Valencia, Imprenta Juan González, 17541755.

Nadault de Buffon, H. (1843): Des canaux d'arrosage de l'Italie septentrionale dans leurs rapports avec ceux du midi de la France..., Paris, 3 vols.

Ordenanzas de la Real Acequia de Moncada..., Valencia, Alcañiz, 1972.

Ostrom, E. (2011): El gobierno de los bienes comunes. La evolución de las instituciones de acción colectiva, México, FCE\&IIS.

Pérez Sarrión, G. (1990): Regadíos, política hidráulica y cambio social en Aragón, siglos XVXVIII, en Pérez Picazo\&Lemeunier (eds.): Agua y modo de producción, Barcelona, Crítica, pp. 212270.

Peris, T. (1992): Regadío, producción y poder en la Ribera del Xúquer. La Acequia Real de Alrira, 1258 1847, Valencia, C.O.P.U.T.\&Confederación Hidrográfica del Júcar.

Peris, T. (2003): Problemas agrícolas y gestión hidráulica en la Huerta de Valencia, en Drain, M. (ed.): Politiques de l'eau en milieu méditerranéen..., Madrid, Casa de Velázquez, pp. 129-150.

Peris, T. (2008): El regadiu. Evolució, organització i transcendència socioeconómica, en Giralt, E. (dir.): Història Agrària..., III, Barcelona, Universidades \& ICR, pp. 125-144.

Peris, T. (2014): El ejercicio de la autonomía local en las acequias de la Huerta de Valencia: la olvidada imbricación municipal (siglos XIII-XIX), Minius, en vías de publicación.

Polop, J.A. (2007): Canals i l'aigua: el riu dels Sants, 1844-1931, Canals, Ayuntamiento.

Román, I. (2000): El regadio de Vila-Real durante los siglos XIII-XV ..., Villareal, Ayuntamiento.

Romero, J. y T. Peris (1992): Usos, distribució i control de l'aigua, en Geografia General..., II, Barcelona, Enciclopèdia Catalana, pp. 186-277.

Romero, J., Peris, T. y Pellicer, R. (1994): Regadíos y estructuras de poder en el Mediterráneo español: la Acequia Real del Xúquer, en Romero y Giménez (eds.): Regadíos y estructuras de poder, Alicante, Gil-Albert, pp. 151-192.

Sala, D. (2007): La milenaria acequia de Mislata, Valencia, Nácher. 
Sanchis, C. (2001): Regadiu i canvi ambiental a l'Albufera de Valencia, Valencia, Departamento de Geografía y CVER.

Sanchis, C. (2013): Las instituciones horizontales de gestión colectiva del riego. El fracaso del Sindicato General de Riegos del Turia (1850-1883), Documentos SEHA, 13-09.

Selma, S. y Guinot, E. (2005): Les séquies de l'Horta Nord de València..., Valencia, Conselleria de Agricultura. 